\title{
CrimRxiv
}

\section{Knowing about Genocide: Armenian Suffering and Epistemic Struggles}

Joachim J. Savelsberg

Published on: Mar 31, 2021

License: Creative Commons Attribution 4.0 International License (CC-BY 4.0). 
